\title{
NSAIDs-induced upper gastrointestinal bleeding in hepatitis B virus-positive patient with acute kidney injury - nonocclusive mesenteric ischemia
}

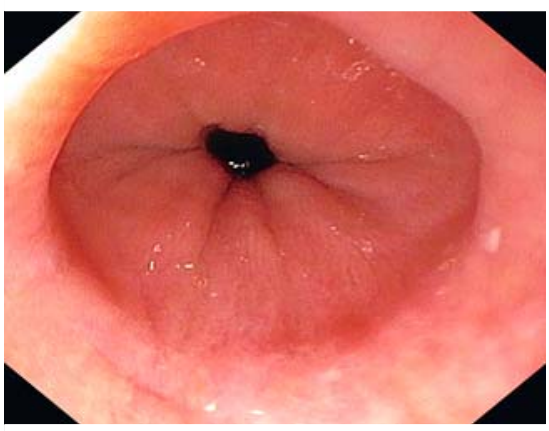

- Fig. 1 Endoscopic appearance of normal distal esophagus and cardia.

An 81-year-old woman was admitted to the intensive care unit with pneumonia complicated by acute kidney injury. Her medical history included arterial hypertension and chronic hepatitis $B$ virus infection. The patient was on dual antiplatelet therapy because of recent myocardial infarction. Antibiotic treatment and continuous renal replacement therapy were started.

Four days after admission, the patient's condition improved and she was moved to the internal medicine unit. Two days later a hemodialysis session was required because of persistent metabolic acidosis, uremia, and hyperkalemia. A few hours later, she presented hypovolemic shock, with melena and a significant hemoglobin drop; coagulation tests were normal. Emergency endoscopy was performed, showing no hemorrhagic stigmata during intubation of the upper gastrointestinal tract ( $\triangleright$ Fig. 1); however, a small amount of fresh blood and clots were aspirated from the third portion of the duodenum ( $\triangleright$ Fig. 2; $\triangleright$ Video 1 ). The third portion of the duodenum presented diffuse ulcerations affecting half of the antimesenteric portion of the circumference, while the mesenteric side was preserved. Interestingly, the second portion and the duodenal bulb showed only small erosions ( $\triangleright$ Fig.3). Surprisingly, despite a normal appearance during intubation, the gas-
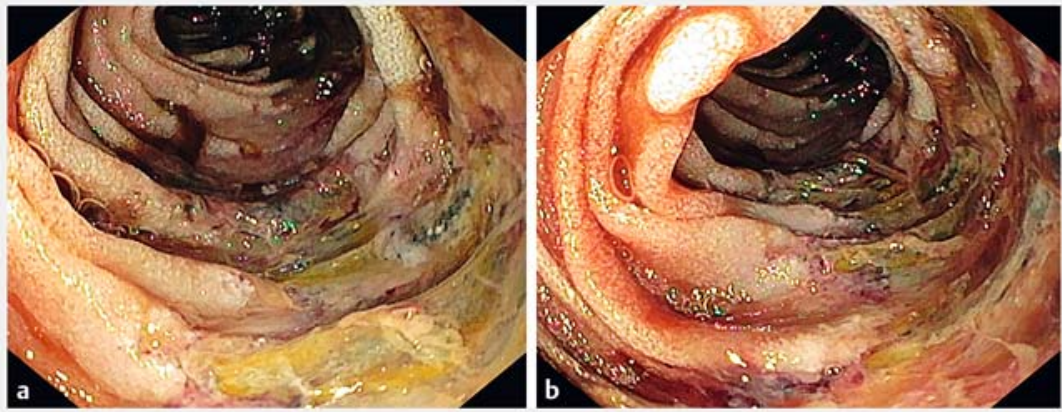

Fig. 2 a, b Endoscopic appearance of severe ischemia of the third portion of the duodenum, with diffuse confluent ulcers, fresh blood, and clots.

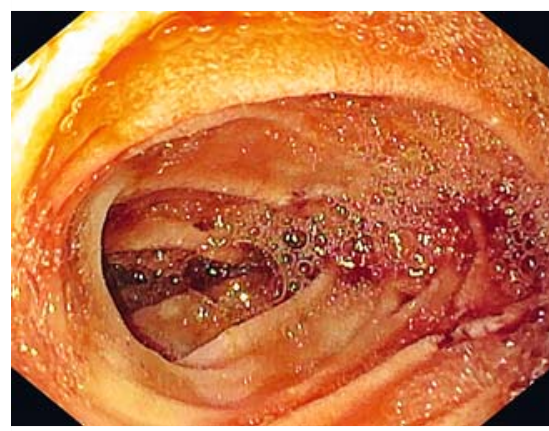

Fig. 3 Second portion of the duodenum with small erosions on the antimesenteric portion.

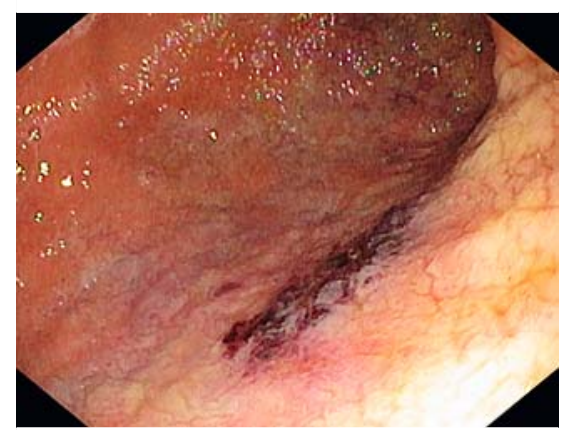

- Fig. 4 Grayish gastric mucosa with large ecchymosis.
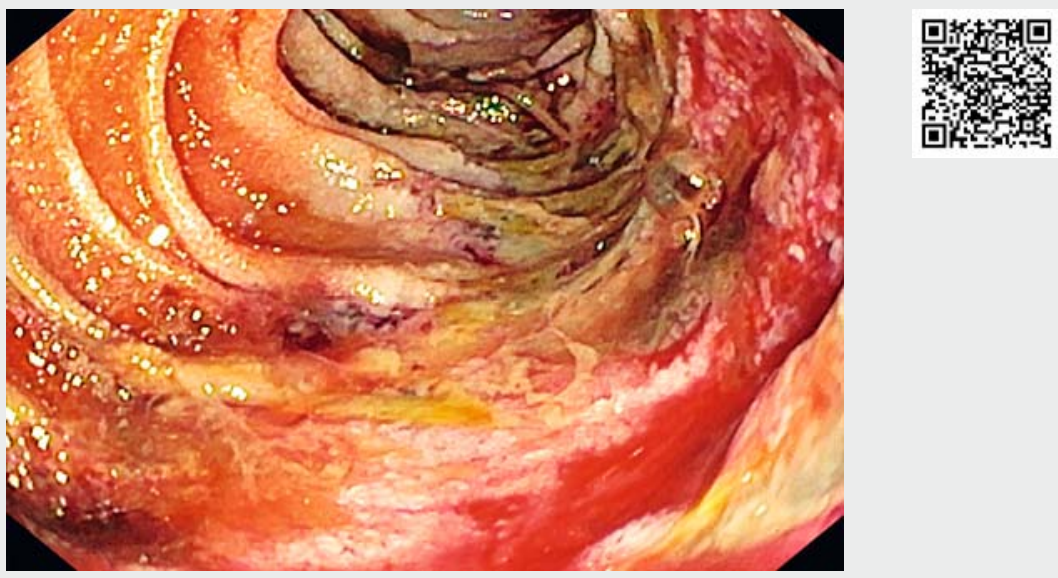

$\checkmark$ Video 1 Urgent upper gastrointestinal endoscopy showing severe ischemia mostly in the third portion of the duodenum in the territory of the superior mesenteric artery. 
tric mucosa had become grayish, with concomitant disappearance of the underlying vascular structure and the appearance of ecchymosis ( $\mathbf{F i g . 4 ) .}$

Nonocclusive mesenteric ischemia (NOMI) is a consequence of splanchnic vasoconstriction coupled with local hypoperfusion. NOMI should be suspected in all patients with cardiac failure or other low-flow state with ischemic involvement of the territory of the superior mesenteric artery, since it accounts for up to $20 \%$ of all cases of acute mesenteric ischemia. In this case, hemodialysis decompensated the patient's precarious circulatory balance [1 - 3]. We think that, in this case, pressure related to insufflation and the mechanical stress of the endoscopic procedure contributed to the "real-time" development of gastric ischemia during the exam [4].

Angiography and surgery were considered to be contraindicated in this patient. She was conservatively treated with resuscitation, fluids, plasma expanders, and blood transfusion, which led to an improvement in her general condition; she survived the event $[1,5]$.

Endoscopy_UCTN_Code_CCL_1AC_2AB

Competing interests

None
The authors

Andrea Lisotti ${ }^{1,2}$, Sinan Sadalla ${ }^{1,2}$, Anna

Cominardi ${ }^{1,2}$, Pietro Fusaroli ${ }^{1,2}$

1 Gastroenterology Unit, Hospital of Imola, Italy

2 Department of Medical and Surgical Sciences, University of Bologna, Italy

\section{Corresponding author}

\section{Andrea Lisotti, MD}

Unità Operativa Complessa di

Gastroenterologia, Ospedale di Imola, via Montericco 9, 40026 Imola (BO), Italy

lisotti.andrea@gmail.com

\section{References}

[1] Bala M, Kashuk J, Moore EE et al. Acute mesenteric ischemia: guidelines of the World Society of Emergency Surgery. World J Emerg Surg 2017; 12: 38

[2] Kärkkäinen JM, Acosta S. Acute mesenteric ischemia (part I) - Incidence, etiologies, and how to improve early diagnosis. Best Pract Res Clin Gastroenterol 2017; 31: 15-25

[3] Trompeter M, Brazda T, Remy CT et al. Non-occlusive mesenteric ischemia: etiology, diagnosis, and interventional therapy. Eur Radiol 2002; 12: 1179-1187

[4] Ahmad DS, Sahak K, Lazenby AJ et al. Chronic mesenteric ischemia and gastric ischemia: a bad combination. Gastrointest Endosc 2017; 86: $564-565$

[5] Kärkkäinen JM, Acosta S. Acute mesenteric ischemia (part II) - Vascular and endovascular surgical approaches. Best Pract Res Clin Gastroenterol 2017; 31: 27-38

\section{Bibliography}

Dol https://doi.org/10.1055/a-0978-4881

Published online: 9.8.2019

Endoscopy 2020; 52: E22-E23

(c) Georg Thieme Verlag KG

Stuttgart · New York

ISSN 0013-726X

\section{ENDOSCOPY E-VIDEOS}

https:/|eref.thieme.de/e-videos

回回 Endoscopy E-Videos is a free ry access online section, reporting 靣触: on interesting cases and new

techniques in gastroenterological endoscopy. All papers include a high quality video and all contributions are freely accessible online.

This section has its own submission website at https://mc.manuscriptcentral.com/e-videos 